\title{
Epidemiology of Isolated Impaired Glucose Tolerance Among Adults Aged Above 50 Years in Rural China
}

\author{
Xiaobing $\operatorname{Tian}^{1, *}$ \\ Yan $\mathrm{Li} \mathbb{1 D}^{2,3, *}$ \\ Jie Liu $(\mathbb{D})^{1,2,4,5, *}$ \\ Qiuxing Lin 1,2,4,5 \\ Qiaoxia Yang ${ }^{6}$ \\ Jun Tu' ${ }^{1,2,4,5}$ \\ Jinghua Wang (D) ${ }^{1,2,4,5}$ \\ Jidong $\mathrm{Li}^{2,7}$ \\ Xianjia Ning ${ }^{1,2,4,5}$
}

'Department of Neurology, Tianjin Medical University General Hospital, Tianjin, People's Republic of China;

${ }^{2}$ Center of Clinical Epidemiology \& Evidence-Based Medicine, The Jizhou People's Hospital, Tianjin, People's Republic of China; ${ }^{3}$ Department of Anesthesiology, The Jizhou People's Hospital, Tianjin, People's Republic of China; ${ }^{4}$ Laboratory of Epidemiology, Tianjin Neurological Institute, Tianjin, People's Republic of China; ${ }^{5}$ Tianjin Neurological Institute, Key Laboratory of Post-Neuroinjury Neuro-Repair and Regeneration in Central Nervous System, Ministry of Education and Tianjin City, Tianjin, People's Republic of China; ${ }^{6}$ Department of Cardiology, Tianjin Medical University General Hospital, Tianjin, People's Republic of China;

${ }^{7}$ Department of Neurosurgery, The Jizhou People's Hospital, Tianjin, People's Republic of China

*These authors contributed equally to this work

\begin{abstract}
Introduction: Isolated impaired glucose tolerance (i-IGT) is a subtype of prediabetes in which an individual demonstrates elevated 2-h post-glucose load glucose levels but normal fasting plasma glucose levels. However, few studies have explored the prevalence and risk factors of i-IGT among adults in rural China. Thus, we aimed to explore the prevalence and risk factors of i-IGT among adults $\geq 50$ years old in a low-income, rural population in China. Materials and Methods: Individuals aged $\geq 50$ years with normal fasting plasma glucose levels were included in the final analysis. Fasting and 2-h venous blood samples were collected to assess the selected parameter measurements.
\end{abstract}

Results: A total of 2175 individuals were included in this study. The i-IGT prevalence was $22.9 \%$ and significantly higher among females than among males $(\mathrm{P}<0.05)$. Older age [odds ratio (OR), 1.606; 95\% confidence interval (CI), 1.101-2.342; $\mathrm{P}=0.014)$, hypertension (OR, 1.554; 95\% CI, 1.152-2.019; $\mathrm{P}=0.004$ ), and central obesity (OR, 1.395; 95\% CI, 1.0991.771; $\mathrm{P}=0.006)$ were associated with $\mathrm{i}-\mathrm{IGT}$. Moreover, white blood cell (OR, 1.089; $95 \%$ CI, 1.009-1.175; $\mathrm{P}=0.029)$, high-sensitivity C-reactive protein (OR, 1.049; 95\% CI, 1.020 1.078; $\mathrm{P}=0.001)$, serum uric acid (OR, 1.0003; 95\% CI, 1.001-1.004; $\mathrm{P}=0.001)$, triglyceride (OR, 1.540; 95\% CI, 1.105-2.147; $\mathrm{P}=0.011$ ), and alanine aminotransferase (OR, 1.012; 95\% CI, 1.004-1.021; $\mathrm{P}=0.004)$ levels were also linked to $\mathrm{i}-\mathrm{IGT}$ in the analyzed population.

Conclusion: Health promotion education and a standardized approach to managing body weight, BP, and lipid and uric acid levels would benefit this low-income population in rural China for reducing the risk of cardiovascular disease.

Keywords: impaired glucose tolerance, prevalence, risk factors, normal fasting plasma glucose, epidemiology

\section{Introduction}

Isolated impaired glucose tolerance (i-IGT) is a subtype of prediabetes that manifests as elevated 2-h post- glucose load plasma glucose (2-h PG) levels in individuals who also exhibit normal fasting plasma glucose (FPG) levels. Prediabetic individuals are of interest to clinicians because they have an increased risk of developing type 2 diabetes. ${ }^{1}$ A nationally representative survey carried out in 2013 showed that the prevalence of diabetes and prediabetes in China was $10.9 \%$ and $35.7 \%$, respectively; thus, approximately 200.4 million males and 187.7 million females were estimated to have prediabetes in China. ${ }^{2}$ Prediabetes increases the risk of hyperglycemia, cardiovascular disease, cognitive impairment, and dementia. ${ }^{3-5}$ Moreover, young people with i-IGT
Correspondence: Xianjia Ning; Jidong Li Email xning@tmu.edu.cn; jd_li_doctor@163.com 
have a 2-fold to 32-fold higher risk of developing hypertension and metabolic syndrome. ${ }^{6}$

Previous studies have shown the estimated prevalence of i-IGT to be between $6.2 \%$ and $9.3 \%$ worldwide. $^{7-9}$ However, in rural areas of Korea, the i-IGT prevalence was $3.7 \%$ for adults $\geq 20$ years old. ${ }^{10}$ By comparison, a nationally representative survey conducted in China in 2010 demonstrated that the prevalence of i-IGT was $11.0 \%$ in males and $10.9 \%$ in females, ${ }^{11}$ with a higher prevalence among rural residents than among urban ones. ${ }^{2}$ However, this study lacks information on i-IGT prevalence among low-income adults in China. Numerous studies have shown that the conventional risk factors, which include older age, family history of diabetes, hypertension, obesity, and hypertriglyceridemia, are also associated with i-IGT development. ${ }^{6,12-14}$ Although 2-h PG levels rise sharply with advancing age, ${ }^{15}$ few studies have reported the factors associated with i-IGT development among low-income, poorly educated populations, and particularly the elderly. In China, more than $50 \%$ of the population resides in rural areas; detecting the prevalence and associated factors of $\mathrm{i}-\mathrm{IGT}$ in this sub-population is crucial in reducing the burden of diabetes in China. Thus, this study aimed to explore the prevalence and risk factors of $\mathrm{i}-\mathrm{IGT}$ among adults $\geq 50$ years old in a low-income, poorly educated population in rural China.

\section{Materials and Methods}

\section{Study Population}

This population-based, cross-sectional study was performed between April and June 2019. The project was designed as previously described. ${ }^{16}$ Briefly, all participants were recruited from the Atherosclerosis Cohort of Tianjin Brain Study, which was conducted in 2014. All residents aged 45 years were qualified to be recruited from 18 administrative villages in Yangjinzhuang Town, Jizhou District, Tianjin, China. Residents aged $<45$ years were not included in this study because many of them were working outside Tianjin. In 2019, we recruited all the survivors of the Atherosclerosis Cohort aged $>50$ years to detect the prevalence and risk factors of i-IGT; we excluded those with cancer, severe psychiatric disturbances, hepatic failure, and serious renal disease. The educational attainment and income of the residents in this area were relatively low. The average number of education years was 4.75 years in 1991 and 5.26 years in
2011. The per capita disposable income was less than 1600 US dollars in 2014. ${ }^{17}$

The present study was approved by the Ethics Committee of Tianjin Medical University General Hospital, and a written consent form was provided by each participant. This study was conducted in accordance with the Declaration of Helsinki.

\section{Data Collection}

A standard questionnaire was used to collect information regarding educational attainment, personal and family income, previous medical history, and lifestyle risk factors. The participants were interviewed face-to-face by professional researchers. Demographic information, such as sex and date of birth, was obtained from existing records.

Lifestyle risk factors included cigarette smoking, alcohol consumption, physical exercise, sleep duration, and snoring. Cigarette smoking was defined as smoking at least 1 cigarette/day for $\geq 1$ year; participants were categorized as non-smokers, former smokers (those who had stopped smoking for $\geq 6$ months), and current smokers. Alcohol consumption was defined as drinking at least $500 \mathrm{~g}$ of alcohol/week for $\geq 1$ year; participants were categorized as non-drinkers, former drinkers (temperance for $\geq 6$ months), and current drinkers. Physical exercise was defined as participation in a moderate or vigorous activity for $\geq 30 \mathrm{~min} /$ day on at least 3 days each week. Sleep durations and snoring habits were based on selfreports.

\section{Measurements}

Anthropometric measurements, including height, weight, waist circumference, blood pressure (BP), and heart rate, were performed by epidemiological researchers. Height and weight assessments were conducted with the participants wearing light clothing without hats or shoes; both measurements were determined using an appropriately prepared ultrasonic instrument with the participant in a fully vertical position. Waist circumference was measured using a non-stretch ruler along the horizontal plane at the midpoint between the top of the iliac crest and the bottom of the costal margin in the midaxillary line. Systolic (SBP) and diastolic (DBP) BPs were obtained using a sphygmomanometer. After 5 minutes of quiet rest, participants were asked to expose their arms to facilitate BP and heart rate measurements; the measurements were repeated $5 \mathrm{~min}$ later, and the average was reported. 
Participants were required to follow a 10-h overnight fast before undergoing oral glucose tolerance tests (OGTTs). They were also required to provide venous blood samples for the determination of levels of FPG, total cholesterol (TC), triglycerides (TG), high-density lipoprotein cholesterol (HDL-C), low-density lipoprotein cholesterol (LDL-C), high-sensitivity C-reactive protein (hs-CRP), serum uric acid (SUA), white blood cells (WBCs), alanine aminotransferase (ALT), aspartate aminotransferase (AST), and total bilirubin (TBIL). Then, 75-g glucose (for 75-g OGTT) was administered to the participants, none of whom had a medical history of diabetes. Additional blood samples were obtained $120 \mathrm{~min}$ after the first glucose administration to measure the 2-h PG levels. All blood samples were immediately delivered to Guangzhou KingMed Diagnostics Group, an independent clinical laboratory, for analysis.

\section{Definitions}

Body mass index (BMI) was calculated as the participant's body mass $(\mathrm{kg})$ divided by the height squared $\left(\mathrm{m}^{2}\right)$. According to the BMI, participants were categorized as normal weight $\left(<24.0 \mathrm{~kg} / \mathrm{m}^{2}\right)$, overweight $(24.0-27.9 \mathrm{~kg}$ / $\left.\mathrm{m}^{2}\right)$, or obese $\left(\geq 28 \mathrm{~kg} / \mathrm{m}^{2}\right) .{ }^{18}$ Central obesity was defined as a waist circumference $>90 \mathrm{~cm}$ for men and $>85 \mathrm{~cm}$ for women. ${ }^{19}$ Hypertension was defined as a SBP $\geq 140$ $\mathrm{mmHg}$, DBP $\geq 90 \mathrm{mmHg}$, or taking antihypertension medications.

Normal glucose tolerance was defined as an FPG level $<5.6 \mathrm{mmol} / \mathrm{L}$ and a $2-\mathrm{h}$ PG level $<7.8 \mathrm{mmol} / \mathrm{L}$. The 3 subtypes of prediabetes were defined as follows: isolated impaired fasting glucose (i-IFG; $5.6 \mathrm{mmol} / \mathrm{L} \leq \mathrm{FPG}<7.0$ $\mathrm{mmol} / \mathrm{L}$ and $2-\mathrm{h}$ PG $<7.8 \mathrm{mmol} / \mathrm{L}), \mathrm{i}-\mathrm{IGT}(\mathrm{FPG}<5.6$ $\mathrm{mmol} / \mathrm{L}$ and $7.8 \mathrm{mmol} / \mathrm{L} \leq 2-\mathrm{h} P G<11.1 \mathrm{mmol} / \mathrm{L})$, and combined IFG and IGT (IFG + IGT; $5.6 \mathrm{mmol} / \mathrm{L} \leq \mathrm{FPG}<$ $7.0 \mathrm{mmol} / \mathrm{L}$ and $7.8 \mathrm{mmol} / \mathrm{L} \leq 2-\mathrm{h} \mathrm{PG}<11.1 \mathrm{mmol} / \mathrm{L}){ }^{11}$ Diabetes was defined as a FPG level $\geq 7.0 \mathrm{mmol} / \mathrm{L}$, a 2 -h PG level $\geq 11.1 \mathrm{mmol} / \mathrm{L}$, a previous history of diagnosed diabetes, or use of antihyperglycemia drugs. ${ }^{20}$

\section{Statistical Analyses}

Continuous variables (age, years of formal education, BMI, SBP, DBP, heart rate, WBC counts, and levels of FPG, 2-h PG, hs-CRP, SUA, TC, TG, HDL-C, LDL-C, ALT, AST, and TBIL) are presented as means with standard deviations; between-group comparisons were made using Student's $t$-tests. Categorical variables (age group, education group, income group, smoking status, alcohol consumption status, number of participants engaged in physical activity, and hypertensive status) are presented as numbers with frequencies, and between-group comparisons were made using chi-squared tests. Binary logistic regression analyses were used to evaluate the associated factors in the univariate and multivariate analyses. The relationships are presented as unadjusted odds ratios (ORs) and 95\% confidence intervals (CIs) in the univariate analysis and adjusted OR (95\% CI) in the multivariate analysis. Two-tailed P-values $<0.05$ were considered statistically significant. SPSS for Windows (version 22.0; IBM, Armonk, NY, USA) was used for all statistical analyses.

\section{Results}

A total of 3130 individuals were recruited into the study. Four hundred eighty-three did not receive OGTTs due to a history of diabetes or other health reasons, and 472 had FPG levels $>6.1 \mathrm{mmol} / \mathrm{L}$. Thus, 2175 individuals were included in the final analysis.

\section{Demographic and Clinical Characteristics}

The 2175 included participants [1172 (53.9\%) females] had a mean age of 64.46 years and a mean of 5.53 years of formal education; more than half of the participants had annual incomes of $<2000$ yuan. The mean BMI $\left(25.45 \mathrm{~kg} / \mathrm{m}^{2}\right)$, SBP (149.03 $\mathrm{mmHg}$ ), DBP (84.66 $\mathrm{mmHg})$, and heart rate $(72.81$ bpm) were determined. Further, $74.6 \%$ of the participants had hypertension, and $64.6 \%$ were overweight or obese. The mean FPG and 2-h PG levels were $5.26 \mathrm{mmol} / \mathrm{L}$ and $6.75 \mathrm{mmol} / \mathrm{L}$, respectively; SUA, ALT, and AST levels were $298.08 \mu \mathrm{mmol} /$ L, 18.08 U/L, and 20.83 U/L, respectively (Table 1).

\section{I-IGT Prevalence by Demographic Characteristics}

Table 2 shows the prevalence of $\mathrm{i}-\mathrm{IGT}$ by demographic characteristics of the participants in this study. The overall prevalence of i-IGT was $22.9 \%$, although it was significantly higher in females $(24.7 \%)$ than in males $(20.8 \%$; $\mathrm{P}=0.034)$. The prevalence of $\mathrm{i}-\mathrm{IGT}$ increased with increasing participant age $(\mathrm{P}<0.001)$, and there was a higher prevalence of $\mathrm{i}-\mathrm{IGT}$ among the less-educated $(\mathrm{P}<0.001)$ and lower-income $(\mathrm{P}=0.026)$ participants.

\section{Factors Associated with I-IGT in the Univariate Analysis}

Female sex, old age, low education level, and low income were associated with $\mathrm{i}-\mathrm{IGT}$ development (all, $\mathrm{P}<0.05$; Table 3). Participants with hypertension and obesity were 
Table I Demographic and Clinical Characteristics of All Participants

\begin{tabular}{|c|c|c|c|}
\hline Category & Men & Women & Total \\
\hline Participants, n, (\%) & $1003(46.1)$ & $1172(53.9)$ & $2175(100)$ \\
\hline Age, means (SD), years & $65.65(7.59)$ & $63.44(7.61)$ & $64.46(7.68)$ \\
\hline \multicolumn{4}{|l|}{ Age groups, n (\%) } \\
\hline $50 \sim$ years & $198(19.7)$ & $394(33.6)$ & $592(27.2)$ \\
\hline $60 \sim$ years & $299(29.8)$ & $296(25.3)$ & $595(27.4)$ \\
\hline $65 \sim$ years & $25 \mathrm{I}(25.0)$ & $268(22.9)$ & $519(23.9)$ \\
\hline$\geq 70$ years & $255(25.4)$ & $214(18.3)$ & $469(21.6)$ \\
\hline Education, means (SD), years & $6.64(2.90)$ & $4.58(3.72)$ & $5.53(3.55)$ \\
\hline \multicolumn{4}{|l|}{ Education, n (\%), } \\
\hline$\leq 6$ years & $495(49.4)$ & $782(66.7)$ & I 277 (58.7) \\
\hline$>6$ years & $508(50.6)$ & $390(33.3)$ & $898(41.3)$ \\
\hline \multicolumn{4}{|l|}{ Income, n, (\%) } \\
\hline$<2000$ yuan & $677(67.5)$ & $767(65.4)$ & $1444(66.4)$ \\
\hline $2000 \sim 6000$ yuan & $300(29.9)$ & $370(31.6)$ & $670(30.8)$ \\
\hline$>6000$ yuan & $26(2.6)$ & $35(3.4)$ & $61(2.8)$ \\
\hline \multicolumn{4}{|l|}{ Smoking status, n (\%) } \\
\hline Never smoking & $242(24.5)$ & $1108(95.3)$ & $1350(62.7)$ \\
\hline Ever smoking & $248(25.1)$ & II (0.9) & $259(12.0)$ \\
\hline Current smoking & $499(50.5)$ & $44(3.8)$ & $543(25.2)$ \\
\hline \multicolumn{4}{|l|}{ Alcohol consumption, n, (\%) } \\
\hline Never drinking & $454(28.4)$ & $1143(97.9)$ & I597 (74.0) \\
\hline Ever drinking & $124(5.7)$ & $7(0.6)$ & $13 \mid(6.1)$ \\
\hline Current drinking & $4 \mid 4(4 \mid .7)$ & $17(1.5)$ & $431(20.0)$ \\
\hline \multicolumn{4}{|l|}{ Sleep duration, n, (\%) } \\
\hline$<5$ hours & III (II.2) & $297(25.5)$ & $408(19.0)$ \\
\hline $5 \sim$ hours & $285(28.8)$ & $354(30.4)$ & $639(29.7)$ \\
\hline $7 \sim$ hours & $518(52.4)$ & $454(39.0)$ & $972(45.1)$ \\
\hline$>9$ hours & $74(7.5)$ & $60(5.2)$ & $134(6.2)$ \\
\hline \multicolumn{4}{|l|}{ Physical exercise, n, (\%) } \\
\hline No & $399(39.8)$ & $445(38.0)$ & $844(38.8)$ \\
\hline Yes & $604(60.2)$ & $727(62.0)$ & $|33|(6 \mid .2)$ \\
\hline \multicolumn{4}{|l|}{ Hypertension, n, (\%) } \\
\hline No & $239(23.9)$ & $313(26.8)$ & $552(25.4)$ \\
\hline Yes & $760(76.1)$ & $857(73.2)$ & $1617(74.6)$ \\
\hline BMI, means (SD), Kg/m2 & $24.88(3.34)$ & $25.94(3.80)$ & $25.45(3.63)$ \\
\hline \multicolumn{4}{|l|}{ BMI, n, (\%) } \\
\hline Normal & $4 I I(4 I .0)$ & $357(30.5)$ & $768(35.4)$ \\
\hline Over weight & $428(42.7)$ & $504(43.1)$ & $932(42.9)$ \\
\hline Obesity & $164(16.4)$ & $308(26.3)$ & $472(21.7)$ \\
\hline \multicolumn{4}{|l|}{ Central obesity, n, (\%) } \\
\hline No & $658(65.6)$ & $587(50.2)$ & $1245(57.3)$ \\
\hline Yes & $345(34.4)$ & $582(49.8)$ & 927 (42.7) \\
\hline
\end{tabular}

(Continued) 
Table I (Continued).

\begin{tabular}{|c|c|c|c|}
\hline Category & Men & Women & Total \\
\hline SBP, means (SD), mmHg & $150.38(20.64)$ & I47.88 (19.38) & $149.03(20.00)$ \\
\hline DBP, means (SD), mmHg & $87.04(11.40)$ & $82.64(10.06)$ & $84.66(10.92)$ \\
\hline $\mathrm{HR}$, means (SD), beats/min & 70.49 (1 I.62) & $72.94(10.62)$ & 71.81 (11.15) \\
\hline FPG, means (SD), mmol/L & $5.27(0.45)$ & $5.26(0.43)$ & $5.26(0.44)$ \\
\hline 2-h PG, means (SD), mmol/L & $6.49(2.16)$ & $6.97(1.83)$ & $6.75(2.00)$ \\
\hline WBC, means (SD), $\times 10^{9} / \mathrm{L}$ & $6.20(1.66)$ & $5.93(1.54)$ & $6.05(1.60)$ \\
\hline hs-CRP, means (SD), mg/L & $2.20(3.94)$ & $2.20(4.13)$ & $2.20(4.04)$ \\
\hline SUA, means (SD), $\mu \mathrm{mmol} / \mathrm{L}$ & $330.01(86.70)$ & $270.75(72.90)$ & $298.08(84.85)$ \\
\hline $\mathrm{TC}$, means (SD), mmol/L & $4.90(0.8 I)$ & $5.29(0.89)$ & $5.11(0.88)$ \\
\hline TG, means (SD), mmol/L & $1.33(1.03)$ & $1.60(0.99)$ & $1.47(1.02)$ \\
\hline HDL-C, means (SD), mmol/L & $1.42(0.47)$ & $\mathrm{I} .43(0.4 \mathrm{I})$ & I.43 (0.44) \\
\hline LDL-C, means (SD), mmol/L & $2.95(0.79)$ & $3.24(0.88)$ & $3.10(0.86)$ \\
\hline ALT, means (SD), U/L & $18.64(15.21)$ & $17.61(10.12)$ & $18.08(12.73)$ \\
\hline AST, means (SD), U/L & $21.42(12.96)$ & $20.33(7.32)$ & $20.83(10.32)$ \\
\hline TBIL, means (SD), $\mu \mathrm{mmol} / \mathrm{L}$ & $11.10(5.04)$ & $9.01(4.07)$ & $9.98(4.66)$ \\
\hline
\end{tabular}

Abbreviations: SD, standard deviation; BMI, body mass index; SBP, systolic blood pressure; DBP, diastolic blood pressure; HR, heart rate; FPG, fasting plasma glucose; 2-h PG, two-hour plasma glucose; WBC, white blood cell; hs-CRP, high-sensitivity C-reactive protein; SUA, serum uric acid; TC, total cholesterol; TG, triglycerides; HDL-C, high density lipoprotein cholesterol; LDL-C, low density lipoprotein cholesterol; CIMT, carotid intima-media thickness.

Table 2 The Prevalence of Isolated Impaired Glucose by Demographic Characteristics

\begin{tabular}{|c|c|c|c|}
\hline Groups & Non-i-IGT & i-IGT & $\mathbf{P}$ \\
\hline Participants n (\%) & 1677 (77.I) & 498 (22.9) & - \\
\hline Sex, n (\%) & & & 0.034 \\
\hline Men & $794(79.2)$ & $209(20.8)$ & \\
\hline Women & $883(75.3)$ & $289(24.7)$ & \\
\hline $\begin{array}{l}\text { Age groups, } \mathrm{n}(\%) \\
\text { 50 years } \\
60 \sim \text { years } \\
65 \sim \text { years } \\
\geq 70 \text { years }\end{array}$ & $\begin{array}{l}483(81.6) \\
475(79.8) \\
392(75.5) \\
327(69.7)\end{array}$ & $\begin{array}{l}109(18.4) \\
120(20.2) \\
127(24.5) \\
1472(30.3)\end{array}$ & $<0.001$ \\
\hline $\begin{array}{l}\text { Education, } \mathrm{n}(\%) \\
\quad \leq 6 \text { years } \\
>6 \text { years }\end{array}$ & $\begin{array}{l}945(74.0) \\
732(81.5)\end{array}$ & $\begin{array}{l}332(26.0) \\
166(18.5)\end{array}$ & $<0.001$ \\
\hline $\begin{array}{l}\text { Income, } n,(\%) \\
<2000 \text { yuan } \\
2000 \sim 6000 \text { yuan } \\
>6000 \text { yuan }\end{array}$ & $\begin{array}{l}1090(75.5)) \\
535(79.9) \\
52(85.2)\end{array}$ & $\begin{array}{l}354(24.5) \\
135(20.1) \\
9(14.8)\end{array}$ & 0.026 \\
\hline
\end{tabular}

Abbreviation: i-IGT, isolated impaired glucose tolerance. also more likely to develop i-IGT (both, $\mathrm{P}<0.001$ ). Further, individuals were more likely to develop i-IGT if they were current drinkers and underwent physical exercise (both, $\mathrm{P}<0.05)$.

Participants with i-IGT had higher heart rates, WBC counts, and levels of hs-CRP, SUA, and ALT than those without i-IGT (all, $\mathrm{P}<0.05$ ). Furthermore, the levels of TC, TG, and LDL-C were significantly higher among participants with i-IGT than among those without i-IGT, but there was an inverse trend for HDL-C levels (all, $\mathrm{P}<0.05$ ).

\section{Multivariate Analysis of the Factors Associated with I-IGT}

In the multivariate analysis, older age, hypertension, central obesity, high WBC counts, and elevated levels of hs-CRP, SUA, TG, and ALT were independent factors associated with $\mathrm{i}-\mathrm{IGT}$ among adults $\geq 50$ years old. When using the $\leq 60$-year-old age group as a reference group, the prevalence of i-IGT was $60.6 \%$ higher among individuals who were $\geq 70$ years old (OR, $1.606 ; 95 \% \mathrm{CI}, 1.101-2.342 ; \mathrm{P}=0.014)$. 
Table 3 The Associated Factors of I-IGT for All Participants in the Univariate Analysis

\begin{tabular}{|c|c|c|c|}
\hline Groups & NGT & i-IGT & $\mathbf{P}$ \\
\hline Sex, n (\%) & & & 0.038 \\
\hline Men & $762(78.5)$ & $209(2 \mid .5)$ & \\
\hline Women & $850(74.6)$ & $289(25.4)$ & \\
\hline Age groups, n (\%) & & & $<0.001$ \\
\hline 50 years & $477(81.4)$ & $109(18.6)$ & \\
\hline 60 years & $456(79.2)$ & $120(20.8)$ & \\
\hline $65 \sim$ years & $376(74.8)$ & $127(25.2)$ & \\
\hline$\geq 70$ years & $303(68.1)$ & $1472(31.9)$ & \\
\hline Education, $\mathrm{n}(\%)$, & & & $<0.001$ \\
\hline$\leq 6$ years & $901(73.1)$ & $332(26.9)$ & \\
\hline$>6$ years & $7 I I(8 I . I)$ & $166(18.9)$ & \\
\hline Income, n, (\%) & & & 0.023 \\
\hline$<2000$ yuan & $1047(74.7)$ & $354(25.3)$ & \\
\hline $2000 \sim 6000$ yuan & $513(79.2)$ & $135(20.8)$ & \\
\hline$>6000$ yuan & $52(85.2)$ & $9(14.8)$ & \\
\hline Smoking status, n (\%) & & & 0.004 \\
\hline Never smoking & $978(74.4)$ & $336(25.6)$ & \\
\hline Ever smoking & $189(75.9)$ & $60(24.1)$ & \\
\hline Current smoking & $428(81.7)$ & $96(18.3)$ & \\
\hline Alcohol consumption, n, (\%) & & & 0.142 \\
\hline Never drinking & II 177 (75.6) & $380(24.4)$ & \\
\hline Ever drinking & $94(74.0)$ & $33(26.0)$ & \\
\hline Current drinking & $328(80.0)$ & $82(20.0)$ & \\
\hline sleep duration, n, (\%) & & & 0.426 \\
\hline$<5$ hours & $287(73.4)$ & $104(26.6)$ & \\
\hline $5 \sim$ hours & $48 I(77.7)$ & $138(22.3)$ & \\
\hline $7 \sim$ hours & $729(76.7)$ & $222(23.3)$ & \\
\hline$>9$ hours & $100(78.1)$ & $28(21.9)$ & \\
\hline Physical exercise, n, (\%) & & & 0.029 \\
\hline No & $648(78.9)$ & $173(2||)$. & \\
\hline Yes & $964(74.8)$ & $325(25.2)$ & \\
\hline Hypertension, n, (\%) & & & $<0.001$ \\
\hline No & $46 I(84.7)$ & $83(15.3)$ & \\
\hline Yes & II $47(73.5)$ & $414(26.5)$ & \\
\hline BMI, n, (\%) & & & $<0.001$ \\
\hline Normal & $613(82.1)$ & I34 (I7.9) & \\
\hline Over weight & $680(75.1)$ & $225(24.9)$ & \\
\hline Obesity & $317(69.7)$ & $138(30.3)$ & \\
\hline Central obesity, n, (\%) & & & $<0.001$ \\
\hline No & $988(81.2)$ & $229(18.8)$ & \\
\hline Yes & 622 (69.9) & $268(30.1)$ & \\
\hline
\end{tabular}

(Continued) 
Table 3 (Continued).

\begin{tabular}{|c|c|c|c|}
\hline Groups & NGT & i-IGT & $\mathbf{P}$ \\
\hline Heart rate, means (SD), beats/min & $71.37(11.05)$ & $73.36(11.52)$ & 0.001 \\
\hline WBC, means (SD), $\times 10^{9} / \mathrm{L}$ & $5.94(1.48)$ & $6.39(1.90)$ & $<0.001$ \\
\hline hs-CRP, means (SD), mg/L & 1.91 (3.29) & $3.04(5.73)$ & $<0.001$ \\
\hline SUA, means (SD), $\mu \mathrm{mmol} / \mathrm{L}$ & $290.65(79.58)$ & $320.16(95.70)$ & $<0.001$ \\
\hline $\mathrm{TC}$, means (SD), mmol/L & $5.08(0.86)$ & $5.21(0.94)$ & 0.004 \\
\hline TG, means (SD), mmol/L & $1.40(0.90)$ & $1.69(1.33)$ & $<0.001$ \\
\hline HDL-C, means (SD), mmol/L & $\mathrm{I} .44(0.44)$ & $\mathrm{I} .37(0.4 \mathrm{I})$ & 0.001 \\
\hline LDL-C, means (SD), mmol/L & $3.08(0.84)$ & $3.18(0.90)$ & 0.025 \\
\hline ALT, means (SD), U/L & $17.54(12.30)$ & $19.83(14.21)$ & 0.001 \\
\hline AST, means (SD), U/L & $20.55(10.25)$ & $21.58(10.86)$ & 0.054 \\
\hline TBIL, means (SD), $\mu \mathrm{mmol} / \mathrm{L}$ & $9.91(4.59)$ & $10.10(4.73)$ & 0.422 \\
\hline
\end{tabular}

Abbreviations: NGT, normal glucose tolerance; i-IGT, isolated impaired glucose tolerance; DM, diabetes mellitus; SD, standard deviation; BMI, body mass index; FPG, fasting plasma glucose; 2-h PG, two-hour plasma glucose; HR, heart rate; WBC, white blood cell; hs-CRP, high-sensitivity C-reactive protein; SUA, serum uric acid; TC, total cholesterol; TG, triglycerides; HDL-C, high density lipoprotein cholesterol; LDL-C, low density lipoprotein cholesterol; CIMT, carotid intima-media thickness.

Participants with hypertension had 55.4\% higher prevalence of $\mathrm{i}-\mathrm{IGT}$ than those with normal BP (OR, 1.554; 95\% CI, 1.152-2.095; $\mathrm{P}=0.004)$. The prevalence of $\mathrm{i}-\mathrm{IGT}$ was also $39.5 \%$ higher among individuals with central obesity compared to individuals without central obesity (OR, 1.395; 95\% CI, 1.099-1.771; $\mathrm{P}=0.006$ ). The prevalence of $\mathrm{i}-\mathrm{IGT}$ increased with each 1 unit increase in the WBC count (8.9\%; OR, 1.089; 95\% CI, 1.009-1.175; $\mathrm{P}=0.029)$, hs-CRP level (4.9\%; OR, 1.049; 95\% CI, 1.020-1.078; $\mathrm{P}=0.001)$, SUA level (0.3\%; OR, 1.0003; 95\% CI, 1.001-1.004; $\mathrm{P}=0.001)$, TG level (54\%; OR, $1.540 ; 95 \%$ CI, 1.105-2.147; $\mathrm{P}=0.011)$, and ALT level (1.2\%; OR, 1.012; 95\% CI, 1.004-1.021; $\mathrm{P}=0.004)$ (Table 4).

\section{Discussion}

In this population-based, cross-sectional study, we explored the i-IGT prevalence and associated factors among adults $\geq 50$ years old in a low-income population in rural China. The overall prevalence of i-IGT was $22.9 \%$, and it was significantly higher among females than males and in low-income, poorly educated individuals. Old age, hypertension, central obesity, and elevated levels of WBCs, hs-CRP, SUA, TG, and ALT were associated with $\mathrm{i}-\mathrm{IGT}$.

Due to population growth, ageing, and dietary transitions, China has witnessed a sharp increase in the prevalence of abnormal glucose regulation..$^{21,22}$ In the current study population, the overall prevalence of i-IGT was $22.9 \%$ and much higher than that reported in other studies. For example, in southern Germany, 35-59-year-old individuals were reported to have an i-IGT prevalence of $6.3 \%$. $^{9}$ Further, a national, cross-sectional survey conducted in Spain demonstrated an i-IGT prevalence of $9.2 \%$ for individuals $\geq 18$ years old. ${ }^{7}$ Consistent with this, a cross-sectional study performed in Shanghai Pudong New District showed that the i-IGT prevalence was $9.2 \%$ for urban residents of China. ${ }^{14}$ In Hubei Province, central China, the prevalence of i-IGT was estimated to be $13.9 \%$ among Han $\geq 40$ years old. ${ }^{23}$ Thus, in this low-income, low education level population, the i-IGT prevalence was much higher than that in urban China. Differences in age, income, and education level of the present study's target population, as well as study design differences, may partly explain the high prevalence of i-IGT in our study population compared with the other study populations. However, the high $\mathrm{i}-\mathrm{IGT}$ prevalence also indicates that OGTTs are essential for the early identification of individuals with abnormal glucose regulation in the target population.

Previous studies have revealed that older age is associated with an increased risk of diabetes. ${ }^{7,11,24}$ For example, a 12-year, prospective study with participants aged 40-69 years showed that older age was independently associated with progression to diabetes (hazard ratio, 1.02; 95\% CI, 1.02-1.03). ${ }^{25}$ Furthermore, the Tehran Lipid and Glucose 
Table 4 The Associated Factors of I-IGT in the Multivariate Analysis

\begin{tabular}{|c|c|c|c|}
\hline Groups & Reference & OR & $\mathbf{P}$ \\
\hline Sex & Women & & \\
\hline Men & & $0.911(0.635,1.308)$ & 0.615 \\
\hline Age groups & 50 years & & \\
\hline 60 years & & $0.967(0.685,1.365)$ & 0.847 \\
\hline 65 years & & $1.344(0.936,1.930)$ & 0.109 \\
\hline$\geq 70$ years & & $1.606(1.101,2.342)$ & 0.014 \\
\hline Education & $>6$ years & & \\
\hline$\leq 6$ years & & $1.195(0.916,1.560)$ & 0.190 \\
\hline Income & $<2000$ yuan & & \\
\hline $2000 \sim 6000$ yuan & & $0.838(0.643,1.091)$ & 0.189 \\
\hline$>6000$ yuan & & $0.676(0.306,1.493)$ & 0.332 \\
\hline Smoking status & Never smoking & & \\
\hline Ever smoking & & $0.875(0.566,1.355)$ & 0.550 \\
\hline Current smoking & & $0.723(0.494,1.059)$ & 0.096 \\
\hline Physical exercise & No & & \\
\hline Yes & & $1.192(0.938,1.515)$ & 0.152 \\
\hline Hypertension & No & & \\
\hline Yes & & $1.554(1.152,2.095)$ & 0.004 \\
\hline Central obesity & No & & \\
\hline Yes & & $1.395(1.099,1.771)$ & 0.006 \\
\hline Heart rate & - & $1.009(0.999,1.019)$ & 0.095 \\
\hline WBC & - & $1.089(1.009,1.175)$ & 0.029 \\
\hline hs-CRP & - & $1.049(1.020,1.078)$ & 0.001 \\
\hline SUA & - & $1.003(1.001,1.004)$ & 0.001 \\
\hline TC & & $0.523(0.254,1.079)$ & 0.079 \\
\hline TG & - & $1.540(1.105,2.147)$ & 0.011 \\
\hline HDL-C & - & $1.737(0.834,3.617)$ & 0.140 \\
\hline LDL-C & - & $1.961(0.979,3.930)$ & 0.057 \\
\hline ALT & & $1.012(1.004,1.021)$ & 0.004 \\
\hline
\end{tabular}

Abbreviations: i-IGT, isolated impaired glucose tolerance; DM, diabetes mellitus; OR, odds ratio; BMI, body mass index; WBC, white blood cell; hs-CRP, highsensitivity C-reactive protein; SUA, serum uric acid; TG, triglycerides; HDL-C, high density lipoprotein cholesterol; CIMT, carotid intima-media thickness.

Study indicated that advanced age ( $\geq 40$ years old) was an important predictor of i-IGT in adults with normal FPG levels. ${ }^{12}$ In the present low-income population, we concluded that older age was an independent risk factor of $\mathrm{i}-\mathrm{IGT}$ among adults $\geq 50$ years old. Insulin secretion decreases by approximately $0.7 \%$ per year as people age; however, this decline in $\beta$-cell function is accelerated approximately 2 -fold in people with IGT, ${ }^{26}$ partly explaining the effect of age on plasma glucose levels.
A positive association between hypertension and diabetes has also been reported in numerous studies. ${ }^{27-29}$ In a metaanalysis of prospective studies involving 4.1 million adults, each $20 \mathrm{mmHg}$-elevation in SBP and $10 \mathrm{mmHg}$-elevation in DBP increased the risk of new-onset diabetes by $58 \%$ and $52 \%$, respectively, when compared with normal $\mathrm{BPs}^{30}$ A population-based survey conducted in Beijing demonstrated that 14-28-year-old individuals with hypertension had a $368 \%$ higher risk of i-IGT than those with normal BP $(<130 / 85 \mathrm{mmHg}){ }^{6}$ Similarly, hypertension was an independent risk factor of i-IGT in the target population of the present study. Diabetes and hypertension are closely related because of their similar risk factors, such as endothelial dysfunction, vascular inflammation, advanced glycation endproducts, and oxidative stress. ${ }^{31,32}$

In the present survey, we concluded that central obesity was an independent risk factor of i-IGT in the target population. Many studies have shown that central obesity is positively associated with diabetes. ${ }^{33-35}$ A rural cohort study conducted in the Henan Province of China indicated that central obesity increased the risk of diabetes by $138 \%$ (OR, 2.38; 95\% CI, 2.11-2.70). ${ }^{36}$ Further, a populationbased, cross-sectional study of adults with normal BMIs in the Jilin Province of China showed a significant association between central obesity and diabetes. ${ }^{37}$ Resistin is an adipocyte-derived cytokine that causes insulin resistance and glucose intolerance in mice. ${ }^{38}$ Increased resistin expression in abdominal fat compared with thigh fat may explain the increased risk of i-IGT associated with central obesity. ${ }^{39}$

Type 2 diabetes presents as a form of inflammatory disease. ${ }^{40}$ Previously, a prospective study in China revealed a U-shaped association between WBC counts and the incidence of diabetes in adults between 18 and 59 years old. ${ }^{41}$ However, other studies indicated that WBC counts are an independent risk factor for the development of diabetes even when the counts are within the normal range. ${ }^{42,43}$ Moreover, a 6-year follow-up study indicated that elevated WBC counts are associated with impaired fasting glycemia risk in Chinese adults. ${ }^{44}$ The increase in WBC counts and the activation of WBCs play a key role in diabetes-induced organ damage and increase in free fatty acid levels caused by microcirculation dysfunction. ${ }^{45,46}$ In addition, in patients with type 2 diabetes and coronary heart disease, higher WBC counts are predictors of atrial fibrillation, all-cause death, and hospitalization for acute myocardial infarction. ${ }^{47}$ In the present study, we demonstrated that elevated WBC counts are an independent risk factor of i-IGT. The elevated WBC counts in patients 
with i-IGT further suggest a role for chronic inflammation in the progression of $\mathrm{i}-\mathrm{IGT}$.

Hs-CRP, produced by the liver, is a nonspecific marker of acute phase, systemic inflammation, and previous studies have shown an association between hs-CRP levels and diabetes. ${ }^{48,49}$ For example, in the Jackson Heart Study, participants with hs-CRP levels in the third tertile demonstrated a higher risk of type 2 diabetes when compared with those in the first tertile of hs-CRP levels (HR 2.07; 95\% CI, 1.67-2.56). ${ }^{50}$ The present study shows that an elevated hs-CRP level is an independent risk factor of $\mathrm{i}-\mathrm{IGT}$ in the target population. Because hs-CRP levels predict changes in insulin secretion and insulin sensitivity, $^{51}$ hs-CRP levels may also predict i-IGT development.

SUA is a purine metabolite that can cause hyperuricemia, gout, and renal failure, and high levels of SUA are associated with an increased risk of IGT and diabetes. ${ }^{52,53}$ A prospective study in Shanghai has revealed that SUA levels are strongly associated with the incidence of diabetes in middle-aged and elderly adults. ${ }^{54}$ Moreover, the Beijing Health Management Cohort has shown that persistent hyperuricemia results in a $75 \%$ increase in the risk of diabetes (risk ratio, 1.75; 95\% CI, 1.47-2.08). ${ }^{55}$ Similarly, we found that SUA levels represent an independent i-IGT risk factor in our study population. High SUA levels can cause inflammation and oxidative stress, ${ }^{56}$ which can partially mediate insulin resistance, ${ }^{57}$ leading to $\mathrm{i}-\mathrm{IGT}$ and diabetes.

Previous studies have shown that TG levels are also associated with a higher risk of diabetes in Chinese adults. ${ }^{11,58,59}$ Furthermore, a study performed in Beijing demonstrated that hypertriglyceridemia increases the risk of i-IGT by $192 \%$ compared with normal TG levels (OR, 2.92; 95\% CI, 1.27-6.73; $\mathrm{P}=0.012){ }^{6}$ In the present study's target population, we found that the prevalence of i-IGT increased by $54 \%$ for each $1 \mathrm{mmol} / \mathrm{L}$-increase in $\mathrm{TG}$ levels. Hence, strict lipid management appears to be essential for this population.

ALT, found in a variety of cells, is most abundant in hepatocytes. Previous studies have revealed that ALT levels are positively associated with diabetes risk. ${ }^{60,61}$ Further, a prospective study in China showed that ALT levels are positively associated with the incidence of diabetes (hazard ratio, 1.12; 95\% CI, 1.02-1.22) after adjusting for nonalcoholic fatty liver disease and other covariates. ${ }^{62}$ In the present study, we concluded that high ALT levels are an independent risk factor of i-IGT. High ALT levels decrease hepatic insulin sensitivity and predict the incidence of type 2 diabetes, ${ }^{63}$ possibly explaining the link between ALT levels and i-IGT development.

This study had several limitations. First, the nature of cross-sectional studies prevents the identification of causal relationships. Second, this study involved only people living in the rural areas of Tianjin, China; therefore, our findings cannot be generalized to other populations. Third, since we did not measure insulin levels, we could not evaluate insulin resistance or insulin secretion. Fourth, residents aged $<50$ years were excluded from this study because there were large proportions of them living outside the area due to work. This may impact the assessment of i-IGT status among younger individuals. Our future studies will evaluate this. Finally, our reliance on self-reported sleep durations may have influenced the accurate assessment of any association between sleep duration and i-IGT.

\section{Conclusion}

In this cross-sectional study conducted in rural China, the overall prevalence of $\mathrm{i}-\mathrm{IGT}$ was $22.9 \%$ among adults $\geq 50$ years old; the i-IGT prevalence was significantly higher among females and individuals with low incomes and low levels of education. The conventional risk factors, including older age, hypertension, central obesity, and elevated TG and SUA levels, were independently associated with a high risk of $\mathrm{i}-\mathrm{IGT}$ development. The results suggest that promoting health education and standardizing the management of body weight, BP, lipid levels, and uric acid levels is essential for this low-income population in rural China.

\section{Abbreviations}

i-IGT, isolated impaired glucose tolerance; OR, odds ratio; CI, confidence interval; 2-h PG, 2-h plasma glucose; FPG, fasting plasma glucose; BPs, blood pressures; SBP, systolic blood pressure; DBP, diastolic blood pressure; OGTTs, oral glucose tolerance tests; $\mathrm{TC}$, total cholesterol; $\mathrm{TG}$, triglycerides; HDL-C, high-density lipoprotein cholesterol; LDL-C, low-density lipoprotein cholesterol; hs-CRP, highsensitivity C-reactive protein; SUA, serum uric acid; WBCs, white blood cells; ALT, alanine aminotransferase; AST, aspartate aminotransferase; TBIL, total bilirubin; BMI, body mass index.

\section{Data Sharing Statement}

The datasets generated during and/or analyzed during the current study are available from the corresponding authors on reasonable request. 


\section{Ethics Approval and Consent to Participate}

The study was approved by the medical research ethics committee at Tianjin Medical University General Hospital; written informed consent was obtained from each participant during recruitment.

\section{Acknowledgments}

We thank all participants of the Tianjin Brain Study, and local medical care professionals for their valuable contributions.

\section{Author Contributions}

All authors made a significant contribution to the work reported, whether that is in the conception, study design, execution, acquisition of data, analysis and interpretation, or in all these areas; took part in drafting, revising or critically reviewing the article; gave final approval of the version to be published; have agreed on the journal to which the article has been submitted; and agree to be accountable for all aspects of the work.

\section{Funding}

There is no funding to report.

\section{Disclosure}

The authors declare no competing financial interests and no conflicts of interest for this work.

\section{References}

1. Morris DH, Khunti K, Achana F, et al. Progression rates from HbA1c 6.0-6.4\% and other prediabetes definitions to type 2 diabetes: a meta-analysis. Diabetologia. 2013;56(7):1489-1493. doi:10.1007/ s00125-013-2902-4

2. Wang L, Gao P, Zhang M, et al. Prevalence and ethnic pattern of diabetes and prediabetes in China in 2013. JAMA. 2017;317 (24):2515-2523. doi:10.1001/jama.2017.7596

3. Rao Kondapally Seshasai S, Kaptoge S, Thompson A, et al. Diabetes mellitus, fasting glucose, and risk of cause-specific death. $N$ Engl $J$ Med. 2011;364(9):829-841.

4. Huang Y, Cai X, Mai W, Li M, Hu Y. Association between prediabetes and risk of cardiovascular disease and all cause mortality: systematic review and meta-analysis. BMJ. 2016;355:i5953. doi:10.1136/bmj. i5953

5. Xue M, Xu W, Ou YN, et al. Diabetes mellitus and risks of cognitive impairment and dementia: a systematic review and meta-analysis of 144 prospective studies. Ageing Res Rev. 2019;55:100944. doi:10.1016/j.arr.2019.100944

6. Li Y, Feng D, Esangbedo IC, et al. Insulin resistance, beta-cell function, adipokine profiles and cardiometabolic risk factors among Chinese youth with isolated impaired fasting glucose versus impaired glucose tolerance: the BCAMS study. BMJ Open Diabetes Res Care. 2020;8(1):e000724. doi:10.1136/bmjdrc-2019-000724
7. Soriguer F, Goday A, Bosch-Comas A, et al. Prevalence of diabetes mellitus and impaired glucose regulation in Spain: the Di@bet.es. Study Diabetologia. 2012;55(1):88-93. doi:10.1007/s00125-011-2336-9

8. Wilmot EG, Edwardson CL, Biddle SJ, et al. Prevalence of diabetes and impaired glucose metabolism in younger 'at risk' UK adults: insights from the STAND programme of research. Diabet Med. 2013;30(6):671-675. doi:10.1111/dme.12173

9. Meisinger C, Strassburger K, Heier M, et al. Prevalence of undiagnosed diabetes and impaired glucose regulation in 35-59-year-old individuals in Southern Germany: the KORA F4 Study. Diabet Med. 2010;27(3):360-362. doi:10.1111/j.1464-5491.2009.02905.x

10. Lee JE, Jung SC, Jung GH, et al. Prevalence of diabetes mellitus and prediabetes in dalseong-gun, Daegu City, Korea. Diabetes Metab J. 2011;35(3):255-263. doi:10.4093/dmj.2011.35.3.255

11. Yang W, Lu J, Weng J, et al. Prevalence of diabetes among men and women in China. $N$ Engl J Med. 2010;362(12):1090-1101. doi:10.1056/NEJMoa0908292

12. Rambod M, Hosseinpanah F, Ardakani EM, Padyab M, Azizi F. Finetuning of prediction of isolated impaired glucose tolerance: a quantitative clinical prediction model. Diabetes Res Clin Pract. 2009;83(1):61-68. doi:10.1016/j.diabres.2008.09.040

13. Zhang F, Wan Q, Cao H, et al. Identical anthropometric characteristics of impaired fasting glucose combined with impaired glucose tolerance and newly diagnosed type 2 diabetes: anthropometric indicators to predict hyperglycaemia in a community-based prospective cohort study in southwest China. BMJ Open. 2018;8(5):e019735. doi:10.1136/bmjopen-2017-019735

14. Qian Q, Li X, Huang X, et al. Glucose metabolism among residents in Shanghai: natural outcome of a 5-year follow-up study. $J$ Endocrinol Invest. 2012;35(5):453-458. doi:10.3275/7854

15. Metter EJ, Windham BG, Maggio M, et al. Glucose and insulin measurements from the oral glucose tolerance test and mortality prediction. Diabetes Care. 2008;31(5):1026-1030. doi:10.2337/dc07-2102

16. Qi D, Liu J, Wang C, et al. Sex-specific differences in the prevalence of and risk factors for hyperuricemia among a low-income population in China: a cross-sectional study. Postgrad Med. 2020;132(6):559567. doi:10.1080/00325481.2020.1761133

17. Center CNHDR. China National Health Accounts Report 2018. 2019.

18. Zhou BF. Effect of body mass index on all-cause mortality and incidence of cardiovascular diseases-report for meta-analysis of prospective studies open optimal cut-off points of body mass index in Chinese adults. Biomed Environ Sci. 2002;15(3):245-252.

19. Tian Y, Jiang C, Wang M, et al. BMI, leisure-time physical activity, and physical fitness in adults in China: results from a series of national surveys, 2000-14. Lancet Diabetes Endocrinol. 2016;4 (6):487-497. doi:10.1016/S2213-8587(16)00081-4

20. Chinese Diabetes Society. Guidelines for the prevention and treatment of type 2 diabetes in China (2017 Edition). Chin J Diabetes. 2018;10(1):4-67. doi:10.3760/cma.j.issn.1674-5809.2014.07.004

21. NCD Risk Factor Collaboration (NCD-RisC). Worldwide trends in diabetes since 1980: a pooled analysis of 751 population-based studies with 4.4 million participants. Lancet. 2016;387 (10027):1513-1530. doi:10.1016/S0140-6736(16)00618-8

22. He Y, Li Y, Yang X, et al. The dietary transition and its association with cardiometabolic mortality among Chinese adults, 1982-2012: a crosssectional population-based study. Lancet Diabetes Endocrinol. 2019;7 (7):540-548. doi:10.1016/S2213-8587(19)30152-4

23. Hu X, Zhang Q, Zeng TS, et al. Not performing an OGTT results in underdiagnosis, inadequate risk assessment and probable cost increases of (pre)diabetes in Han Chinese over 40 years: a population-based prospective cohort study. Endocr Connect. 2018;7 (12):1507-1517. doi:10.1530/EC-18-0372

24. Liu L, Zhou C, Du H, et al. The prevalences of impaired fasting glucose and diabetes mellitus in working age men of North China: Anshan Worker Health Survey. Sci Rep. 2014;4:4835. doi:10.1038/ srep04835 
25. Han SJ, Kim HJ, Kim DJ, Lee KW, Cho NH. Incidence and predictors of type 2 diabetes among Koreans: a 12-year follow up of the Korean Genome and Epidemiology Study. Diabetes Res Clin Pract. 2017;123:173-180. doi:10.1016/j.diabres.2016.10.004

26. Szoke E, Shrayyef MZ, Messing S, et al. Effect of aging on glucose homeostasis: accelerated deterioration of beta-cell function in individuals with impaired glucose tolerance. Diabetes Care. 2008;31 (3):539-543. doi:10.2337/dc07-1443

27. Tsimihodimos V, Gonzalez-Villalpando C, Meigs JB, Ferrannini E. Hypertension and Diabetes Mellitus: coprediction and Time Trajectories. Hypertension. 2018;71(3):422-428. doi:10.1161/ HYPERTENSIONAHA.117.10546

28. Tatsumi Y, Ohkubo T. Hypertension with diabetes mellitus: significance from an epidemiological perspective for Japanese. Hypertens Res. 2017;40(9):795-806. doi:10.1038/hr.2017.67

29. Kim MJ, Lim NK, Choi SJ, Park HY. Hypertension is an independent risk factor for type 2 diabetes: the Korean genome and epidemiology study. Hypertens Res. 2015;38(11):783-789. doi:10.1038/hr.2015.72

30. Emdin CA, Anderson SG, Woodward M, Rahimi K. Usual blood pressure and risk of new-onset diabetes: evidence from 4.1 million adults and a meta-analysis of prospective studies. J Am Coll Cardiol. 2015;66(14):1552-1562. doi:10.1016/j.jacc.2015.07.059

31. Libianto R, Batu D, MacIsaac RJ, Cooper ME, Ekinci EI. Pathophysiological links between diabetes and blood pressure. Can J Cardiol. 2018;34(5):585-594. doi:10.1016/j.cjca.2018.01.010

32. Petrie JR, Guzik TJ, Touyz RM. Diabetes, Hypertension, and cardiovascular disease: clinical insights and vascular mechanisms. Can J Cardiol. 2018;34(5):575-584. doi:10.1016/j.cjca.2017.12.005

33. Feng Y, Yang Y, Ma X, et al. Prevalence of diabetes among Han, Manchu and Korean ethnicities in the Mudanjiang area of China: a cross-sectional survey. BMC Public Health. 2012;12:23. doi:10.1186/ 1471-2458-12-23

34. Ohnishi H, Saitoh S, Takagi S, et al. Incidence of type 2 diabetes in individuals with central obesity in a rural Japanese population: the Tanno and Sobetsu study. Diabetes Care. 2006;29(5):1128-1129. doi:10.2337/dc06-0222

35. Hartaigh B, Jiang CQ, Bosch JA, et al. Independent and combined associations of abdominal obesity and seated resting heart rate with type 2 diabetes among older Chinese: the Guangzhou Biobank Cohort Study. Diabetes Metab Res Rev. 2011;27(3):298-306. doi:10.1002/dmrr.1178

36. Abdulai T, Li Y, Zhang H, et al. Prevalence of impaired fasting glucose, type 2 diabetes and associated risk factors in undiagnosed Chinese rural population: the Henan Rural Cohort Study. BMJ Open. 2019;9(8):e029628. doi:10.1136/bmjopen-2019-029628

37. Zhang P, Wang R, Gao C, et al. Prevalence of central obesity among adults with normal BMI and its association with metabolic diseases in Northeast China. PLoS One. 2016;11(7):e0160402. doi:10.1371/journal.pone.0160402

38. Steppan CM, Bailey ST, Bhat S, et al. The hormone resistin links obesity to diabetes. Nature. 2001;409(6818):307-312. doi:10.1038/ 35053000

39. McTernan CL, McTernan PG, Harte AL, Levick PL, Barnett AH, Kumar S. Resistin, central obesity, and type 2 diabetes. Lancet. 2002;359(9300):46-47. doi:10.1016/S0140-6736(02)07281-1

40. Donath MY, Shoelson SE. Type 2 diabetes as an inflammatory disease. Nat Rev Immunol. 2011;11(2):98-107. doi:10.1038/nri2925

41. Du X, Zhu B, Hu G, et al. U-shape association between white blood cell count and the risk of diabetes in young Chinese adults. Diabet Med. 2009;26(10):955-960. doi:10.1111/j.14645491.2009.02801.x

42. Twig G, Afek A, Shamiss A, et al. White blood cells count and incidence of type 2 diabetes in young men. Diabetes Care. 2013;36 (2):276-282. doi:10.2337/dc11-2298
43. Zhang H, Yang Z, Zhang W, et al. White blood cell subtypes and risk of type 2 diabetes. J Diabetes Complications. 2017;31(1):31-37. doi:10.1016/j.jdiacomp.2016.10.029

44. Zang X, Meng X, Wang Y, et al. Six-year follow-up study on the association between white blood cell count and fasting blood glucose level in Chinese adults: a community-based health examination survey. Diabetes Metab Res Rev. 2019;35(4):e3125. doi:10.1002/ dmrr.3125

45. Azekoshi Y, Yasu T, Watanabe S, et al. Free fatty acid causes leukocyte activation and resultant endothelial dysfunction through enhanced angiotensin II production in mononuclear and polymorphonuclear cells. Hypertension. 2010;56(1):136-142. doi:10.1161/ HYPERTENSIONAHA.110.153056

46. Wolf D, Ley K. Immunity and Inflammation in Atherosclerosis. Circ Res. 2019;124(2):315-327. doi:10.1161/CIRCRESAHA.118.313591

47. Kawabe A, Yasu T, Morimoto T, et al. WBC count predicts heart failure in diabetes and coronary artery disease patients: a retrospective cohort study. ESC Heart Fail. 2021. doi:10.1002/ehf2.13513

48. Wang C, Yatsuya H, Tamakoshi K, et al. Positive association between high-sensitivity $\mathrm{C}$-reactive protein and incidence of type 2 diabetes mellitus in Japanese workers: 6-year follow-up. Diabetes Metab Res Rev. 2013;29(5):398-405. doi:10.1002/dmrr.2406

49. Parrinello CM, Lutsey PL, Ballantyne CM, Folsom AR, Pankow JS, Selvin E. Six-year change in high-sensitivity C-reactive protein and risk of diabetes, cardiovascular disease, and mortality. Am Heart J. 2015;170(2):380-389. doi:10.1016/j.ahj.2015.04.017

50. Effoe VS, Correa A, Chen H, Lacy ME, Bertoni AG. HighSensitivity C-Reactive protein is associated with incident type 2 diabetes among African Americans: the Jackson heart study. Diabetes Care. 2015;38(9):1694-1700. doi:10.2337/dc15-0221

51. Fizelova M, Jauhiainen R, Kangas AJ, et al. Differential associations of inflammatory markers with insulin sensitivity and secretion: the prospective METSIM Study. J Clin Endocrinol Metab. 2017;102 (9):3600-3609. doi:10.1210/jc.2017-01057

52. Juraschek SP, McAdams-Demarco M, Miller ER, et al. Temporal relationship between uric acid concentration and risk of diabetes in a community-based study population. Am J Epidemiol. 2014;179 (6):684-691. doi:10.1093/aje/kwt320

53. Bombelli M, Quarti-Trevano F, Tadic M, et al. Uric acid and risk of new-onset metabolic syndrome, impaired fasting glucose and diabetes mellitus in a general Italian population: data from the Pressioni Arteriose Monitorate E Loro Associazioni study. J Hypertens. 2018;36(7):1492-1498. doi:10.1097/ HJH.0000000000001721

54. Wang T, Bi Y, Xu M, et al. Serum uric acid associates with the incidence of type 2 diabetes in a prospective cohort of middle-aged and elderly Chinese. Endocrine. 2011;40(1):109-116. doi:10.1007/ s12020-011-9449-2

55. Liu J, Tao L, Zhao Z, et al. Two-year changes in hyperuricemia and risk of diabetes: a five-year prospective cohort study. J Diabetes Res. 2018;2018:6905720. doi:10.1155/2018/6905720

56. Sautin YY, Nakagawa T, Zharikov S, Johnson RJ. Adverse effects of the classic antioxidant uric acid in adipocytes: NADPH oxidase-mediated oxidative/nitrosative stress. Am J Physiol Cell Physiol. 2007;293(2):C584-596. doi:10.1152/ajpcell.00600.2006

57. Furukawa S, Fujita T, Shimabukuro M, et al. Increased oxidative stress in obesity and its impact on metabolic syndrome. J Clin Invest. 2004;114(12):1752-1761. doi:10.1172/JCI21625

58. Lin D, Qi Y, Huang C, et al. Associations of lipid parameters with insulin resistance and diabetes: a population-based study. Clin Nutr. 2018;37(4):1423-1429. doi:10.1016/j.clnu.2017.06.018

59. Guerrero-Romero F, Rodríguez-Moran M. Hypertriglyceridemia is associated with development of metabolic glucose disorders, irrespective of glucose and insulin levels: a 15-year follow-up study. Eur J Intern Med. 2014;25(3):265-269. doi:10.1016/j.ejim.2014.01.015 
60. Wang YL, Koh WP, Yuan JM, Pan A. Association between liver enzymes and incident type 2 diabetes in Singapore Chinese men and women. BMJ Open Diabetes Res Care. 2016;4(1):e000296. doi:10.1136/bmjdrc-2016-000296

61. De Silva N, Borges MC, Hingorani AD, et al. Liver function and risk of type 2 diabetes: bidirectional Mendelian randomization study. Diabetes. 2019;68(8):1681-1691.
62. Shen X, Cai J, Gao J, et al. Nonalcoholic fatty liver disease and risk of diabetes: a prospective study in China. Endocr Pract. 2018;24 (9):823-832. doi:10.4158/EP-2018-0098

63. Vozarova B, Stefan N, Lindsay RS, et al. High alanine aminotransferase is associated with decreased hepatic insulin sensitivity and predicts the development of type 2 diabetes. Diabetes. 2002;51 (6):1889-1895. doi:10.2337/diabetes.51.6.1889

\section{Publish your work in this journal}

Diabetes, Metabolic Syndrome and Obesity: Targets and Therapy is an international, peer-reviewed open-access journal committed to the rapid publication of the latest laboratory and clinical findings in the fields of diabetes, metabolic syndrome and obesity research. Original research, review, case reports, hypothesis formation, expert opinion and commentaries are all considered for publication. The manuscript management system is completely online and includes a very quick and fair peer-review system, which is all easy to use. Visit http://www.dovepress.com/testimonials.php to read real quotes from published authors. 